\title{
Gas-Chromatographic Technique for Rapid Isolation of Uranium Fission Products *
}

\author{
H. O. Denschlag and A. A. Gordus \\ Department of Chemistry, University of Michigan \\ Received November 8, 1966
}

Summary. A gas-chromatographic technique for a rapid separation of fission iodine or bromine from the other elements formed in nuclear fission was developed. Recoil-formed, volatile methyl bromide and methyl iodide were isolated within $1 \mathrm{~min}$ after the end of irradiation. An extension of this technique to other elements and to other nuclear reactions should be possible.

The $\gamma$-ray spectra of both halogen fractions were measured. A dominating $\gamma$-ray at $0.79 \mathrm{MeV}$ and a weaker $\gamma$-ray at $0.51 \mathrm{MeV}$ were assigned to ${ }^{88} \mathrm{Br}$ (half life $16 \mathrm{sec}$ ). No $\gamma$-ray could be unambiguously attributed to ${ }^{137} \mathrm{I}(24 \mathrm{sec})$, a fact which makes unlikely the presence of highly intensive peaks in the $\gamma$-ray spectrum of this isotope. Further details of the spectra are discussed.

\section{Introduction}

In the study of many nuclear reactions such as fission, time is an important factor in chemical analysis. Most primary fission fragments are short lived $\beta^{-}$emitting isotopes which decay before they can be isolated by classical analytical chemistry from the complex mixture of the more than 30 different elements formed. An attempt has been made here to use "Hot Atom Chemistry" in combination with gas chromatography for selective and rapid chemical separations.

Many chemical reactions of fission products activated by the recoil associated with fission are known or have been predicted: Reactions of fission iodine and/or bromine with gaseous methane $[1,2]$, gaseous $n-p e n-$ tane $[4,5]$, liquid benzene $[2,4,8]$ and many other organic products $[5,9]$ forming mainly the corresponding halides have been detected. Reactions of fission tellurium and selenium with carbon monoxide forming COSe and COTe in analogy to COS have been predicted [7].

In the present study gaseous methane has been chosen as a reaction partner because the reaction products are easily separated by gas chromatography.

\section{Experimental}

A uniform layer of $\mathrm{UO}_{2}$ (natural $\mathrm{U}$, or enriched in ${ }^{235} \mathrm{U}, 0,1-1 \mathrm{mg} / \mathrm{cm}^{2}$ in thickness, has been deposited on one side of a rectangular $(1.8 \times 2.8 \mathrm{~cm})$ aluminium sheet using a modification of the electrodeposition method of DeNschlac and Herrmann [3].

* Dedicated to Prof. Dr. F. Strassmann on his 65th birthday. 
The aluminium sheet has been rolled to a cylinder and placed in a $1.4 \mathrm{ml}$ plastic irradiation vial as shown in Fig.1. (The size is limited by the pneumatic tube facilities and capacity of the gas-chromatographic columns.) The recoil range of the fission products is higher than the average path through $\mathrm{UO}_{2}$ and methane gas inside the vial. Because recoil atoms projected into the opposite wall would not be able to react with methane the $\mathrm{UO}_{2}$ has been coated with a layer of "Krylon" lacquer ( $1 \mathrm{mg} / \mathrm{cm}^{2}$ in thickness) so as to slow down the fragments before they enter

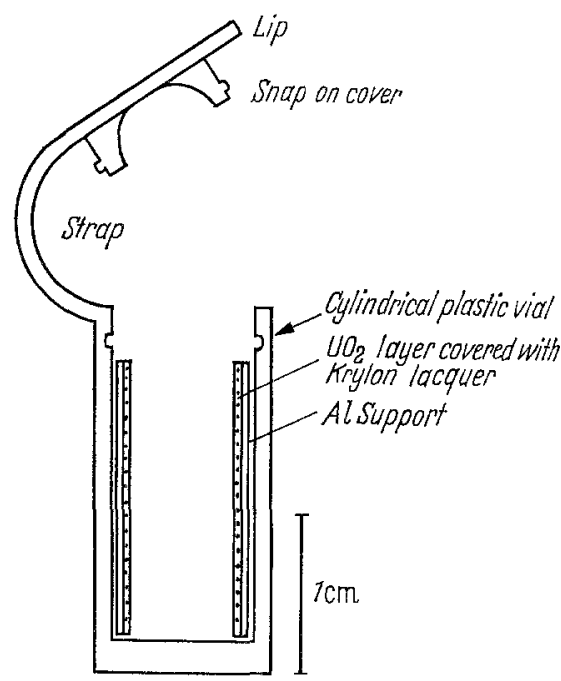

Fig. 1

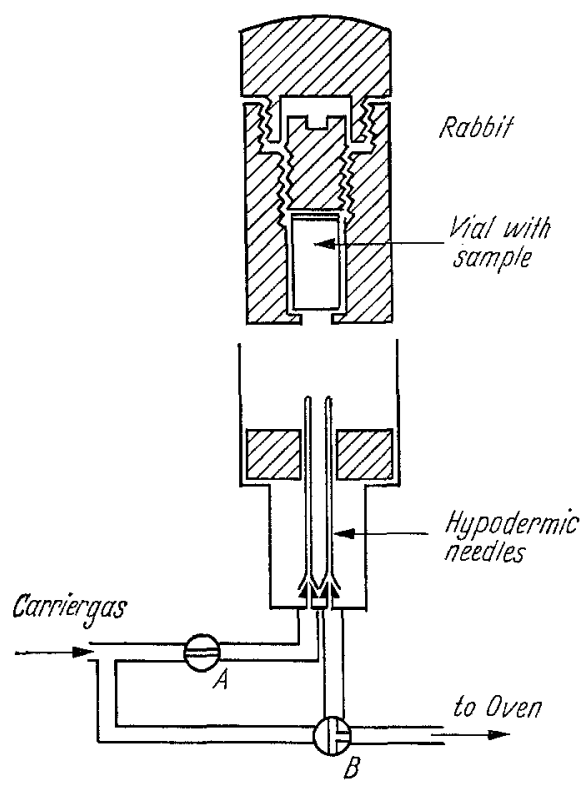

Fig. 2

Fig. 1. Irradiation vial with $\mathrm{UO}_{2}$-covered aluminium sheet

Fig.2. Fast injection system and "rabbit"

the gas phase. The vial was filled with methane gas, closed and placed in a special irradiation rabbit which allowed a rapid injection of the gaseous content into the gas chromatograph after the irradiation. Rabbit and injection system are shown in Fig. ${ }^{1}$. The column used in the present study was $1 \mathrm{~m}$ in length. The stationary phase was 550 Dow silicone oil $(25 \%)$ on Chromosorb P (Mesh $40-60)$. Helium was used as carrier gas. Inlet pressure was 20 psig. The temperature varied from $20^{\circ} \mathrm{C}$ to $150^{\circ} \mathrm{C}$ according to retention time wanted (fraction collected). The resulting flow rate was about $200 \mathrm{ml} / \mathrm{min}$. The radioactivity was detected by two proportional counting tubes facing an external counting volume $(13 \mathrm{ml})$. The separated compounds could be condensed in two charcoal traps which could be alternatively brought into the flowstream by a three-way stopcock.

A typical experiment is performed as follows. The vial is filled with methane inside a little glove box. It is then placed into the rabbit (Fig.2). The stopcocks (A and B) of the injection system are turned as shown in Fig.2. The rabbit is sent into the reactor core through the pneumatic tube. The irradiation is carried out for the

${ }^{1}$ Rabbit and injection system have been developed by M. Tsoukatos for fast injections of liquid gas-chromatographic samples. The authors wish to express their thanks for the use of this system. 
time required. The sample is sent back to the laboratory, caught manually, transferred to the injection system and pushed onto the hypodermic needles of the injection system. Immediately the methane and the volatile organic compounds are swept onto the column by the carrier gas. About 3 sec after the injection stopcock A is closed and $B$ is turned to bypass the injection system. The different compounds emerging from the gas-chromatographic column are then trapped on charcoal.

\section{Results}

A radio gas-chromatogram of the volatile compounds formed in an irradiation with methane is shown in Fig. 3. For the purpose of better identification a longer column $(2 \mathrm{~m})$ has been chosen in this case. The main components formed are $\mathrm{CH}_{3} \mathrm{Br}$ and $\mathrm{CH}_{3} \mathrm{I}$ with smaller amounts of $\mathrm{C}_{2} \mathrm{H}_{3} \mathrm{I}$

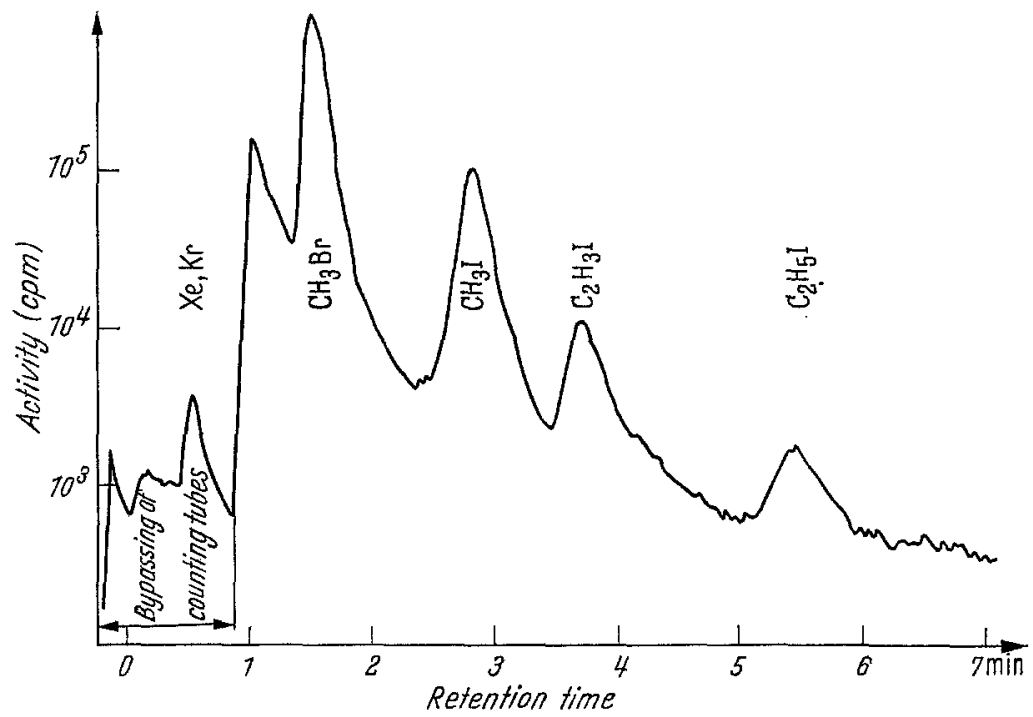

Fig. 3. Radio gas-chromatogram of volatile reaction products formed in the interaction of fission recoil atoms with gaseous methane ( $2 \mathrm{mg}{ }^{235} \mathrm{U}$ irradiated for $3 \mathrm{sec}$ ). Column: $2 \mathrm{~m}$ in length, $3 \mathrm{~mm}$ in diameter, glass tubing filled with $25 \% 550$ Dow silicone oil on Chromosorb $\mathrm{P}$ ( $40-60$ mesh). Flowrate carrier gas: $120 \mathrm{ml} \mathrm{He} / \mathrm{min}$. Temperature: $63^{\circ} \mathrm{C}$. Inlet pressure: $16 \mathrm{psig}$

and $\mathrm{C}_{2} \mathrm{H}_{5} \mathrm{I}$. The chemical yield for $\mathrm{CH}_{3} \mathrm{I}$ and $\mathrm{CH}_{3} \mathrm{Br}$ was of the order of $1 \%$ of the iodine (and bromine) formed by fission. The purity of the peaks has been demonstrated by gamma spectroscopy and by comparison of the specific gamma- $(0.86 \mathrm{MeV}$ line) and $\beta$-activities of the collected compounds.

Except for the specific case where rare-gas isotopes were to be analysed, these gases, which were the first peaks to emerge from the column, were led directly to the hood in order that the counting tubes not be contaminated by radioactive daughter products of the rare gases. The presence of these peaks is seen nevertheless due to incomplete shielding of the detector. In Fig. 3 bypassing was ended too soon and a portion of the tail of the $\mathrm{Xe}+\mathrm{Kr}$ peak is seen. 
Fig. 4 shows a radio gas-chromatogram under the actual conditions of a fast separation. The end of bypassing and the beginning of the methylbromide peak coincide. Unfortunately because of the damping of the recorder the left basis point of the methyl-bromide peak cannot be read. The chromatogram gives an idea of the time needed for the separations. A more detailed listing of the time required for the handling of an experiment is given in the Table.

Even with the rather simple set-up used, one is able to separate iodine, bromine, and the rare gases from 30 other elements and to isolate each of them within less than 1 minute. One should be able to attain separation

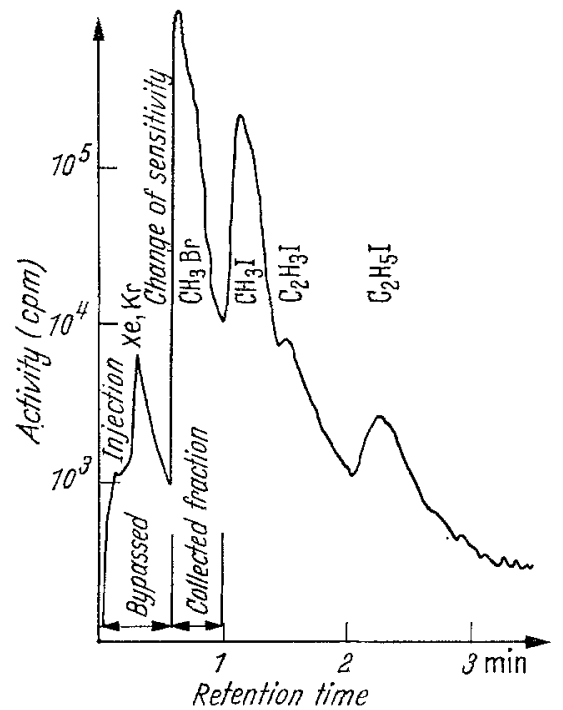

Fig. 4. Radio gas-chromatogram of volatile reaction products under the conditions used for fast isolation of $\mathrm{CH}_{3} \mathrm{Br}$ fraction. Column: $1 \mathrm{~m}$ in length, $3 \mathrm{~mm}$ in diameter, glass tubing filled with $25 \% 550 \mathrm{Dow}$ silicone oil on Chromosorb P (40-60 mesh). Flowrate carrier gas; $300 \mathrm{ml} \mathrm{He} / \mathrm{min}$. Temperature: $25^{\circ} \mathrm{C}$. Inlet pressure: 14 psig

Table. Time schedule for a typical irradiation and isolation of fission iodine or bromine

\begin{tabular}{lcc}
\hline Description of procedure & $\begin{array}{l}\text { Time needed } \\
\text { (sec) }\end{array}$ & $\begin{array}{l}\text { Running time counted from end } \\
\text { point of irradiation until the end } \\
\text { of procedure described (sec) }\end{array}$ \\
\hline $\begin{array}{l}\text { Transportation from laboratory } \\
\quad \text { to reactor core }\end{array}$ & 5 & -1 \\
Irradiation & 1 & 0 \\
Transportation from reactor & 5 & 5 \\
$\quad$ core to laboratory & 4 & 9 \\
Transfer to injection system & 4 & 13 \\
Injection & & 58 \\
Gas-chromatographic separation & 45 & 5 \\
$\quad$ and condensation & & \\
5 Z. Anal. Chem., Bd. 220 &
\end{tabular}


times of the order of tens of seconds by automating the procedure and using capillary columns.

Contamination by an element from a neighboring peak has been smaller than $5 \%$ in all cases. No contamination from other elements could be detected.

\section{Application to nuclear studies}

In an attempt to determine the applicability of this method, gamma spectra of the quickly isolated halogen- and xenon-fractions have been measured.

\section{Xenon fraction}

Fission-xenon and -krypton have been studied by WAHLGREN and MEINKE [10]. Measurements of the gamma spectra were made less than 1 minute after the end of irradiation.

A measurement of the xenon fraction has nevertheless been repeated to check the procedure and to rule out impurity effects in the other fractions. Xenon has been collected in charcoal traps cooled to $-20^{\circ} \mathrm{C}$. Under these conditions the condensation of krypton has been found to be negligible. The spectra recorded ${ }^{2}$ are identical in shape to those of WAHLGREN and METNKe.

\section{Bromine and iodine fractions}

For both iodine and bromine, short lived isotopes (24 sec-137 $\mathrm{I}$ and 16 sec- ${ }^{88} \mathrm{Br}$ ) are known from delayed neutron measurements. The gamma spectra of these isotopes could not be measured previously because fast enough separations were not available. JoHNson and O'KELLEY [6] who established the decay scheme of ${ }^{136} \mathrm{I}$ ( $83 \mathrm{sec}$ ), WILLIAMs and CoRyELL [11] who studied ${ }^{86} \mathrm{Br}(54 \mathrm{sec})$ and ${ }^{87} \mathrm{Br}(55 \mathrm{sec})$ were able to do the isolation within 2.5-4 min. Nevertheless Wincrams and CoryeuL [11] could detect a $0.76 \mathrm{MeV}$ gamma line of a half life shorter than 54/55 sec $\left({ }^{86 / 87} \mathrm{Br}\right)$ in a fraction of secondary fission bromine isolated even $2.5 \mathrm{~min}$ after the end of the irradiation. They assigned this line to ${ }^{88} \mathrm{Br}$.

\section{Methyl-bromide fraction}

Spectra of the $\mathrm{CH}_{3} \mathrm{Br}$ fraction are shown in Fig. 5. A short-lived gamma line is found at an energy of $0.79 \mathrm{MeV}$ and another short-lived contribution at $0.51 \mathrm{MeV}$ is indicated. The other lines shown are the main gamma lines of ${ }^{86} \mathrm{Br}(54 \mathrm{sec})$ and ${ }^{87} \mathrm{Br}(55 \mathrm{sec})$. These decay with exactly the above half lifes when the number of counts under the peak area is

a For these spectra as well as for the iodine and bromine spectra the small charcoal traps ( $2 \mathrm{ml}$ content) were placed directly on a $1 \mathrm{~g} / \mathrm{cm}^{2}$ plastic absorber on top of a $3 \times 3$ inches $\mathrm{NaI}(\mathrm{TI})$ crystal. Spectra were recorded by a 400 channel RIDL analyzer, stored on magnetic tape and printed out later. 
plotted versus time. At $0.40 \mathrm{MeV}$ a contribution of ${ }^{84} \mathrm{Br}$ ( $6 \mathrm{~min}$ ) is found. Plots of the decay of the two new lines at 0.79 and $0.51 \mathrm{MeV}$ show a $16 \mathrm{sec}$ half life after subtraction of a 54/55 sec component (Fig. 6 and 7). A later spectrum of the same sample (curve 5 of Fig.5), although very weak as expected, indicates the presence of both radioactive daughter

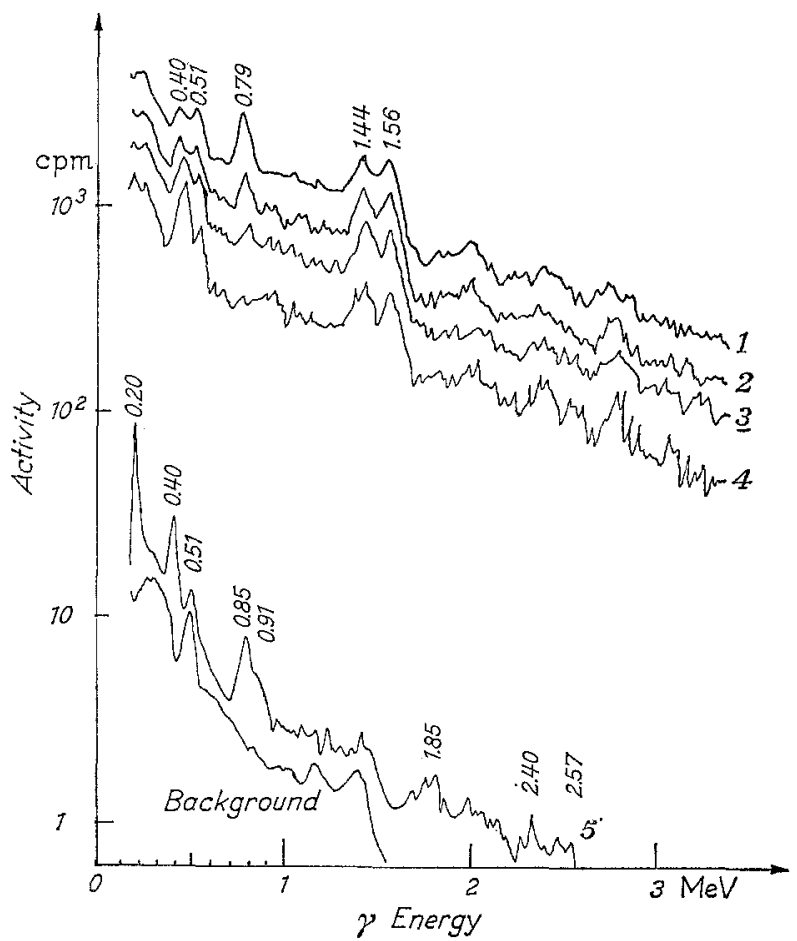

Fig. 5. Series of gamma spectra of the $\mathrm{CH}_{3} \mathrm{Br}$ fraction adjusted to equal count length. Irradiation length: 2.5 sec. Injection: $10-15$ sec after end of irradiation. Collection: $35-50$ sec after end of irradiation. Mean time of gamma measurements (min after end of irradiation) and-in parenthese duration of count (min) corrected for dead time: $l 1.3(0.3) ; 21.8(0.3) ; 32.25(0.3) ; 43.15(0.3)$; $5374(120)$

substances ${ }^{87} \mathrm{Kr}(0.40,2.57,0.85 \mathrm{MeV})$ and ${ }^{88} \mathrm{Kr} /{ }^{88} \mathrm{Rb}(0.19,2.40,0.85 / 1.85$, $0.91 \mathrm{MeV})$. A possible origin of the two new lines from an impurity due to either one of the neighboring gas chromatographic peaks $\mathrm{Xe}(\mathrm{Kr})$ and $\mathrm{CH}_{3} \mathrm{I}$ can be ruled out by comparison with the spectra of both pure fractions. It has therefore been concluded in accordance with WrLliams and CoRYelL [11] that the gamma spectrum of ${ }^{88} \mathrm{Br}$ is dominated by a strong line at $0.79 \mathrm{MeV}$. A weaker line at $0.51 \mathrm{MeV}$ is also present. The possibility that this peak is due to annililation radiation of positrons produced by (undetected) higher energetic $\gamma$ radiation of the ${ }^{88} \mathrm{Br}$ nucleus is unlikely, but cannot be ruled out completely. No other lines could be detected. Indication of high energy $\beta$ - radiation has also been found. 


\section{Methyl-iodide fraction}

Looking at the spectra of the methyl-iodide fraction (Fig. 8) no strong gamma line decaying with the half life of ${ }^{137} \mathrm{I}(24 \mathrm{sec})$ could be detected.

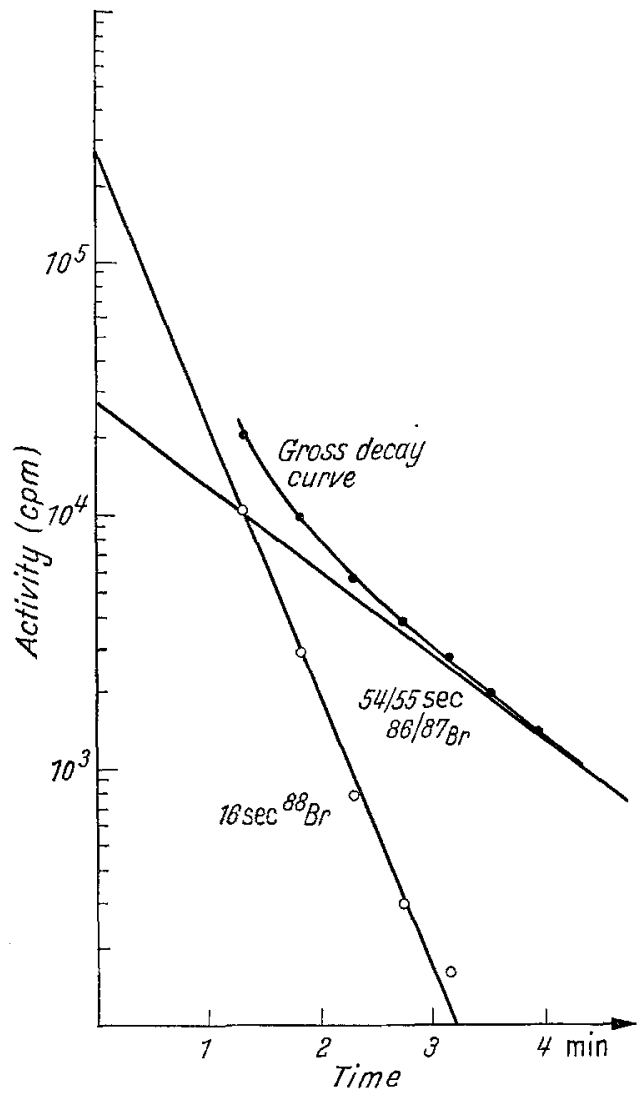

Fig. 6

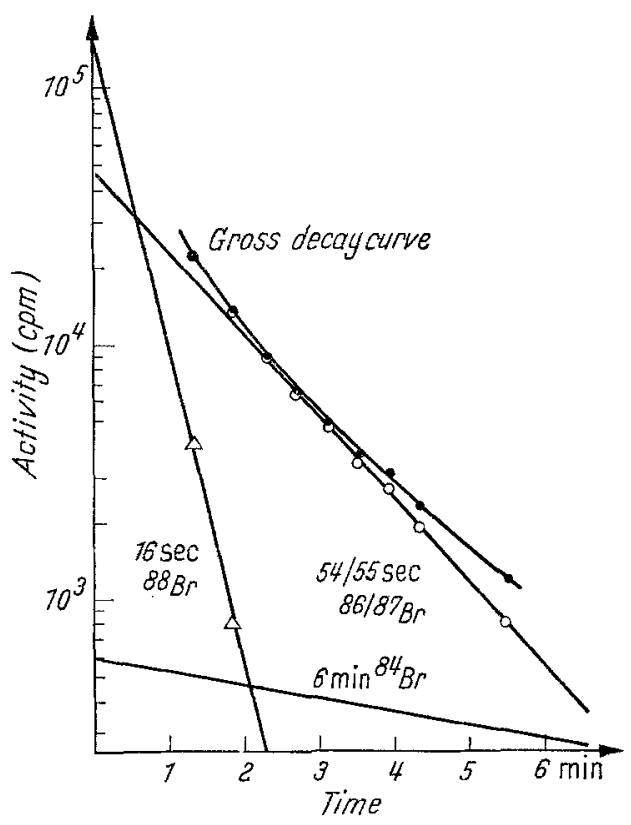

Fig. 7

Fig. 6. Decay of $0.79 \mathrm{MeV}$ gamma line of $\mathrm{CH}_{3} \mathrm{Br}$ fraction (Fig.5). Full circles: gross decay. Blank circles: points resulting after substraction of $54 / 55$ sec component of ${ }^{80 / 87} \mathrm{Br}$

Fig. 7. Decay of $0.51 \mathrm{MeV}$ gamma line of $\mathrm{CH}_{3} \mathrm{Br}$ fraction (Fig.5). Full circles: gross decay. Blank circles: points resulting after substraction of 6 min component of ${ }^{84} \mathrm{Br}$. Triangles: points resulting after additional subtraction of $54 / 55$ see component of ${ }^{88 / 87} \mathrm{Br}$

Fig. 8. Series of gamma spectra of the $\mathrm{CH}_{3} \mathrm{I}$ fraction adjusted to equal count length. Irradiation length: 4 sec. Injection: $10-15$ sec after end of irradiation. Collection: $30-60$ sec after end of irradiation. Mean time of gamma measurements (min after end of irradiation) and-in parentheses--duration of count (mid) corrected for dead time: $11.4(0.3) ; 22.55(0.3) ; 34.3(0.3) ; 46.6(0.3)$

Fig. 9. Decay of $0.27 \mathrm{MeV}$ gamma line of $\mathrm{CH}_{3} \mathrm{I}$ fraction (Fig.8) with indication of two alternative half lifes for the short lived component $(83 \mathrm{sec}$ and $60 \mathrm{sec}$ ). Full circles: gross activity. Triangles: points resulting from the difference of gross activity and the back extrapolated 3.9 min half life of ${ }^{137} \mathrm{Xe}$. Squares: decay of the ${ }^{137} I$ mother resulting from the difference of the back extrapolated line of 60 sec half life and the activity values of the short lived component (triangles)

Fig. 10. Decay of $0.39 \mathrm{MeV}$ and $1.31 \mathrm{MeV}$ garnma lines of the $\mathrm{CH}_{3} \mathrm{I}$ fraction (Fig. 9). Full circles: gross decay, blank circles: decay after subtraction of longer lived background 

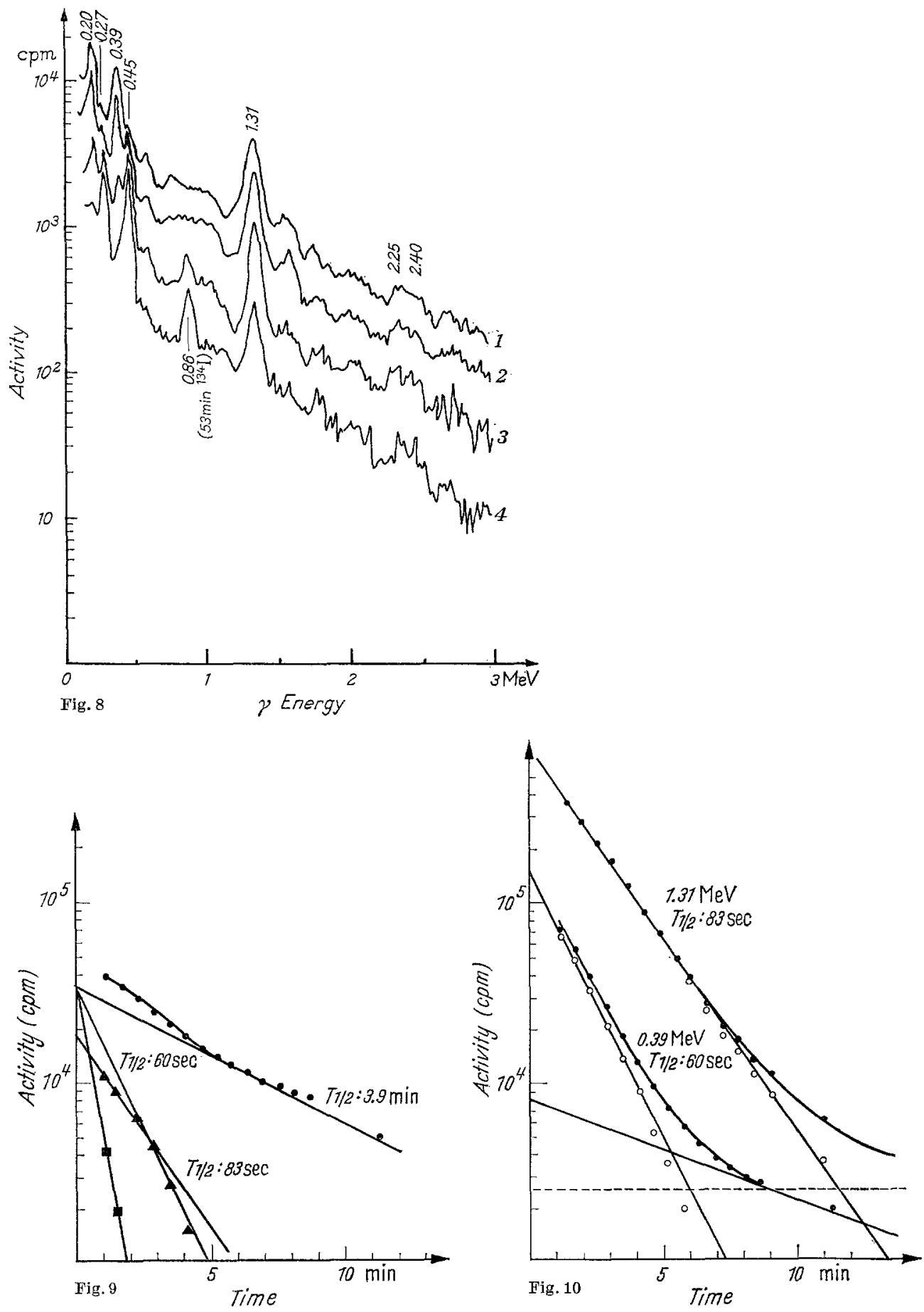

Figs. 8-10. For legends see p. 68 
Comparison of successive decay spectra suggests the presence of a number of weak lines. The presence of the daughter substance ${ }^{137} \mathrm{Xe}$ has been shown by its two characteristic gamma lines $(0.26$ and $0.45 \mathrm{MeV})$ decaying with the half life of $3.9 \mathrm{~min}$ (Fig.9). The $0.45 \mathrm{MeV}$ line also shows the build up of ${ }^{137} \mathrm{Xe}$ by the decay of ${ }^{137} \mathrm{I}$ with a half life of 24 sec. In Fig. 9 this build up is masked by another short-lived line, the half life of which seems to be shorter than 83 sec. If a half life of $60 \mathrm{sec}$ is assumed both the expected amount and half life of ${ }^{137} \mathrm{I}$ parent result. For the $0.39 \mathrm{MeV}$ line also a half life of 60 sec results (Fig.10) when plotted. versus time. Further experiments are needed to decide whether the 60 sec half life is due to a mixture of 24 sec. $^{137} \mathrm{I}$ and $83 \mathrm{sec}^{136} \mathrm{I}$ or not. All other gamma lines present show a half life very close to the 83 sec value of ${ }^{136} \mathrm{I}$ (see $1.32 \mathrm{MeV}$ line, Fig. 10). The strong $0.27 \mathrm{MeV}$ gamma line decaying with a half life of 83 sec found by JoHnson and $O^{\prime}$ Kexiex could not be reproduced. It must be concluded that the detection of this line was not due to ${ }^{136} \mathrm{I}$. This is supported by the fact that the $0.27 \mathrm{MeV}$ line had not been found to be in coincidence with any other ${ }^{136} 1$ gamma line by these authors.

\section{Zusammeniassung}

Eine gaschromatographische Methode zur schnellen Isolierung von Spaltjod oder Spaltbrom aus dem Gemisch der bei der Kernspaltung entstehenden Elemente wurde entwickelt. Mittels Spaltrückstoß gebildetes, flüchtiges Methylbromid oder Methyljodid wurde innerhalb $1 \mathrm{~min}$ nach Bestrahlungsende isoliert. Die Methode sollte auf andere Elemente und andere Kernreaktionen übertragbar sein.

$\gamma$-Spektren der beiden Halogenfraktionen wurden gemessen und ergaben für ${ }^{88} \mathrm{Br}$ (Halbwertszeit $16 \mathrm{sec}$ ) eine dominierende Linie bei $0,79 \mathrm{MeV}$ und eine schwache Linie bei $0,51 \mathrm{MeV}$. In der Jodfraktion wurde keine $\gamma$-Linie beobachtet, die man eindeutig ${ }^{137} \mathrm{~J}(24 \mathrm{sec})$ hätte zuordnen können, was sehr intensive Peaks im Spektrum dieses Isotops unwahrscheinlich macht. Weitere Einzelheiten der Spektren werden diskutiert.

Acknowledgement. We wish to thank the staff of The University of Michigan Nuclear Reactor, especially Messrs. J. Jones, H. Olson and B. Martin for friendly assistance. Many thanks to Dr. K. Rengan, P. Laflevr, M. Tsoukatos, and M. WaKat. One of us (H. O. D.) gratefully acknowledges a grant of the "Adolf Todt" Stiftung. This work was supported by the U.S.Atomic Energy Commission, Division of Research. This is AEC. document No. COO-912-7.

\section{References}

[1] Denschlag, H. O.: Dissertation, Mainz 1965. - [2] Denschlag, H. O., N. Henzel, and G. Herrmann: Radiochim. Acta 1, 172 (1963). - [3] DenschlaG, H. O., and G. Herrmann: Nukleonik 4, 277 (1962). - [4] GordUs, A. A., and 
M. P. Tsoukatos: Gas-Chromatographic separation of chemical reaction products formed by ${ }^{235} \mathrm{U}$ fission recoil. Contribution to the 151st National Meeting of the American Chemical Society, Pittsburgh (Pa.), March 22-31 (1966). - [5] HeIDE, F. zUR: Diplomarbeit, Mainz 1965. - [6] Johrson, N. R., and G. D. O'KeLLEY: Phys. Rev. 114, 279 (1959). - [7] LeE, E. K. C., Y. N. TANG, and F. S. RowLand: J. Phys. Chem. 68, 318 (1964). - [8] Onmond, D., and F. S. Rowland: J. Am. Chem. Soc. 83, 1006 (1961). - [9] Tsoukatos, M. P.: private communication. - -10$]$ WaHLGREN, M. A., and W. W. Merivke: J. Inorg. Nucl. Chem. 24, 1527 (1962). - [11] Willtams, E. T., and C. D. Coryeld: Phys. Rev. 144, 945 (1966).

Dr. H. O. Denschlag.

Department of Chemistry

University of California

Irvine/California
Prof. A. A. Gordus

Department of Chemistry

University of Michigan

Ann Arbor/Michigan

\title{
Schnelle radiochemische Trennungen durch Isotopen- und Ionenaustausch an vorgeformten Niederschlägen *
}

\author{
Wolfram Eckhardt, Günter Herrmany und \\ HANS-DieTER SchÜSSLER \\ Institut für Anorganische Chemie und Kernchemie der Universität Mainz
}

Eingegangen am 3. Dezember 1966

Summary. Short-lived nuclides can be isolated by rapid isotopic and ion exchange between their solutions and preformed precipitates by sucking the solution quickly through a thin layer of the precipitate. It is shown with silver halides, caesium, barium, and thallium compounds how the exchange depends upon the preparation, amount and solubility of the precipitate, and upon the composition and contact time of the solution. In a few systems not only the surface layer but the whole precipitate or most of it is involved in the rapid exchange. As an application an automatic separation procedure is described for bromine and iodine nuclides from fission products by exchange with silver chloride, which can be completed within 2 seconds after irradiation.

Bei der Kernspaltung entstehen, verteilt auf 40 Elemente, Hunderte von kurzlebigen Nukliden, die zum großen Teil noch unbekannt sind [16]. Thre Ausbeuten zeigen, wie Spaltreaktionen ablaufen [17]; ihr Zerfall macht Kerneigenschaften deutlich, über die man noch wenig weiß [2]. Für solche Studien müssen die Nuklide innerhalb von Sekunden isoliert werden. Bewährte Fällungsmethoden versagen meist, weil zuviel Zeit vergeht, bis ein filtrierbarer Niederschlag entstanden ist. Dennoch lassen sich Fällungsmethoden heranziehen, wenn man sie zu Isotopen- oder Ionenaustauschreaktionen an vorgeformten Niederschlägen abwandelt: Der

* Hermn Prof. Dr. F. Strassmann zum 65. Geburtstag gewidmet. 